\title{
Rusted Root of Ginseng (Panax quinquefolius) Is Caused by a Species of Rhexocercosporidium
}

\author{
R. D. Reeleder, S. M. T. Hoke, and Yun Zhang
}

Agriculture and Agri-Food Canada, 1391 Sandford Street, London, ON N5V 4T3, Canada. Accepted for publication 12 June 2006.

\begin{abstract}
Reeleder, R. D., Hoke, S. M. T., and Zhang, Y. 2006. Rusted root of ginseng (Panax quinquefolius) is caused by a species of Rhexocercosporidium. Phytopathology 96:1243-1254.

Rusted root (also known as rusty root) of ginseng (Panax quinquefolius) was first described over 70 years ago, but the causal agent has not been clearly established. The disease is characterized by slightly raised reddish-brown to black root lesions of varying size. The lesions, regardless of size, remain superficial; however, peridermal tissue is ruptured and sloughed off, giving the root a scabbed appearance. Culture-independent techniques were used to demonstrate that a fungal internal transcribed spacer (ITS) region DNA fragment was strongly associated with diseased but not healthy root tissue. The fragment ( $\approx 650$ bp in length) was cloned. Restriction enzyme digests of cloned DNA indicated that the 650-bp fragment represented a single taxon. BLAST analysis following sequencing of the fragment found that the nearest matches in GenBank were

anamorphic genera associated with discomycetes, in particular Rhexocercosporidium spp. This putative identification was supported further by isolating fungi from diseased tissue using a semiselective agar medium. With this procedure, a Rhexocercosporidium-like fungus was isolated; DNA extracted from fungal cultures and amplified using ITS oligonucleotide primers was found to be identical to similarly amplified DNA from the 650-bp bands. However, the isolates were distinct, with respect to growth rate on agar media and ITS sequence, from Rhexocercosporidium carotae, the only described species in this genus. The ability to reproduce symptoms on ginseng roots was confirmed in pathogenicity tests. Oligonucleotide primers based on ITS sequences were designed to amplify DNA of Rhexocercosporidium spp. Polymerase chain reaction assays on DNA extracted from naturally infected root tissue showed that the fungus was present in nearly all symptomatic roots but was infrequent in healthyappearing roots. The most probable cause of rusted root of ginseng is a previously undescribed species of Rhexocercosporidium.
\end{abstract}

Dried roots of Panax quinquefolius L., a species of ginseng indigenous to eastern North American forests, are widely used as ingredients in traditional herbal medicines $(10,30)$. Most of the world supply of dried root is now provided by crops grown under artificial shade structures in various regions of North America. Mean annual production (1999 to 2003) of dried root in the Canadian province of Ontario $(\mathrm{ON})$ was 971 megagrams $(\mathrm{Mg})$ (21). During the same period, the province of British Columbia (BC) produced $741 \mathrm{Mg}$ annually, whereas the American state of Wisconsin reported average yearly sales (1999 to 2003) of 296 $\mathrm{Mg}(6,20)$. Crops typically are grown for a 3- or 4-year period in raised beds (2). The shade structure, coupled with dense plantings and the use of a cereal straw mulch to provide thermal protection to roots, combine to create environments favorable to root and foliar pathogens. Important root diseases include disappearing root rot (caused by Cylindrocarpon destructans f. sp. panacis), Phytophthora root rot (caused by Phytophthora cactorum), and rusted root $(5,22,27,28)$. The latter disease (also known as rusty root or "the rust") first was described in detail by Hildebrand (13), who isolated strains of Ramularia from root lesions and proposed that these strains were the causal agents. Hildebrand carried out some initial pathogenicity assays but did not fully describe the isolates or their effects on roots. He was the first to clearly differentiate disappearing root rot from rusted root, recognizing them as distinct diseases with different causal agents.

Corresponding author: R. D. Reeleder; E-mail address: reelederr@agr.gc.ca

* The $\boldsymbol{e}$-Xtra logo stands for "electronic extra" and indicates that the online version contains supplemental material not included in the print edition. Figures 1 and 6 appear in color online.

DOI: $10.1094 /$ PHYTO-96-1243

For the Department of Agriculture and Agri-Food, Government of Canada, (C) Minister of Public Works and Government Services Canada 2006
A number of Ramularia spp. described by previous workers $(13,33)$ later were transferred to Cylindrocarpon destructans $(8$, 17). Some of the Ramularia isolates obtained by Hildebrand from roots with symptoms of rusted root or disappearing root rot may have been weakly aggressive strains of $C$. destructans, as described by Seifert et al. (28). Hildebrand also isolated other genera (including Fusarium spp.) from diseased roots, but concluded that they were not pathogenic to ginseng.

Rusted root disease is characterized by slightly raised reddish brown to black root lesions of varying size (Fig. 1) $(5,13)$. Small blister-like lesions expand and coalesce to form large lesions that possess a diffuse margin (Fig. 1A to $\mathrm{C}$ ). The peridermal tissue often becomes very dark red, almost black, in color as the disease progresses (22). The lesions, regardless of size, remain superficial; however, peridermal tissue is ruptured and sloughed off, giving the root a pitted or scabbed appearance (Fig. 1D and E). Fragments of the blackened and ruptured periderm may remain attached to the root at harvest. When roots have been dried, lesions often appear light brown in color. Except where symptoms are severe, the disease appears to have little effect on yield (13); however, the discolored, scabby, and often deformed appearance of diseased roots reduces their value. The term "rusty root" also is applied to this disease; however, Hildebrand's use of "rusted root" has historical precedence and may be preferable, in part due to the use of "rusty root" to refer to other unrelated problems that occasionally are observed on roots (2).

Little additional work has been carried out with respect to causal agents of rusted root, although reports have suggested that weakly aggressive strains of $C$. destructans $(5,7,28)$ or isolates of Fusarium equiseti (24) are associated with the disease. The objective of the work reported here was to utilize a culture-independent method to identify the cause of rusted root. A portion of these results has been summarized previously (Reeleder and Hoke [26]). 


\section{MATERIALS AND METHODS}

DNA extraction, internal transcribed spacer region amplification, and electrophoresis. Roots (1 to 4 years old) with symptoms of rusted root were obtained in fall 2004 and spring 2005 from growers located in southwestern ON (Norfolk and Brant counties) and south-central BC (Squamish-Lillooet, ThompsonNicola, and Kootenay Boundary regional districts), the main North American production regions for this crop. Additional roots ( 2 to 5 years old) were obtained from plantings at the Delhi, ON, research farm of Agriculture and Agri-Food Canada. Roots were washed with tap water, and diseased tissue $(\approx 1 \mathrm{~cm}$ long by $0.5 \mathrm{~cm}$ wide and $1 \mathrm{~mm}$ deep) was excised with a sterile scalpel. Tissue samples were collected from roots with a range of symptoms, from young lesions with intact periderm to old lesions with badly ruptured periderm and a scabbed appearance. Roots with similar symptoms also were set aside for isolation of causal agents (described below). Asymptomatic healthy tissue also was excised from roots that appeared to be free of rusted root, or from regions of apparently healthy tissue on diseased roots.
DNA was extracted from tissue using DNeasy Plant Mini kits (Qiagen, Mississauga, ON). Excised tissue was placed in sterile $1.5-\mathrm{ml}$ microcentrifuge tubes, then either ground with a sterile micropestle in the presence of liquid $\mathrm{N}_{2}$ or homogenized in the presence of buffer AP1 (Qiagen) and sterile zirconium oxide beads ( $1 \mathrm{~mm}$ in diameter) using a Retsch MM301 mixer mill. The kit protocol was modified to provide 30 min rather than 10 min of incubation of frozen or homogenized tissue in buffer AP1. Extracts were eluted in buffer $\mathrm{AE}$ and stored at $-20^{\circ} \mathrm{C}$. DNA in extracts was amplified using the internal transcribed spacer (ITS)5 (5'-GGAAGTAAAAGTCGTAACAAGG-3')/ITS4 (5'-TCCTCCGCTTATTGATATGC-3') primer set (31) with amplification conditions as follows. After an initial denaturing period of $60 \mathrm{~s}$ at $95^{\circ} \mathrm{C}$, template DNA was amplified for 30 cycles (denaturing at $94^{\circ} \mathrm{C}$ for $60 \mathrm{~s}$, annealing at $52^{\circ} \mathrm{C}$ for $30 \mathrm{~s}$, and extension at $72^{\circ} \mathrm{C}$ for $60 \mathrm{~s}$ ), followed by a final extension period of $7 \mathrm{~min}$ at $72^{\circ} \mathrm{C}$. Reactions then were cooled to $4{ }^{\circ} \mathrm{C}$ prior to freezing at $-20^{\circ} \mathrm{C}$. Each $50-\mu \mathrm{l}$ reaction was composed of $31.2 \mu$ l of sterile molecular-grade water, $5 \mu \mathrm{l}$ of $10 \times$ polymerase chain reaction (PCR) buffer, $5 \mu \mathrm{l}$ of $25 \mathrm{mM} \mathrm{MgCl} 2,20 \mu \mathrm{g}$ of bovine serum
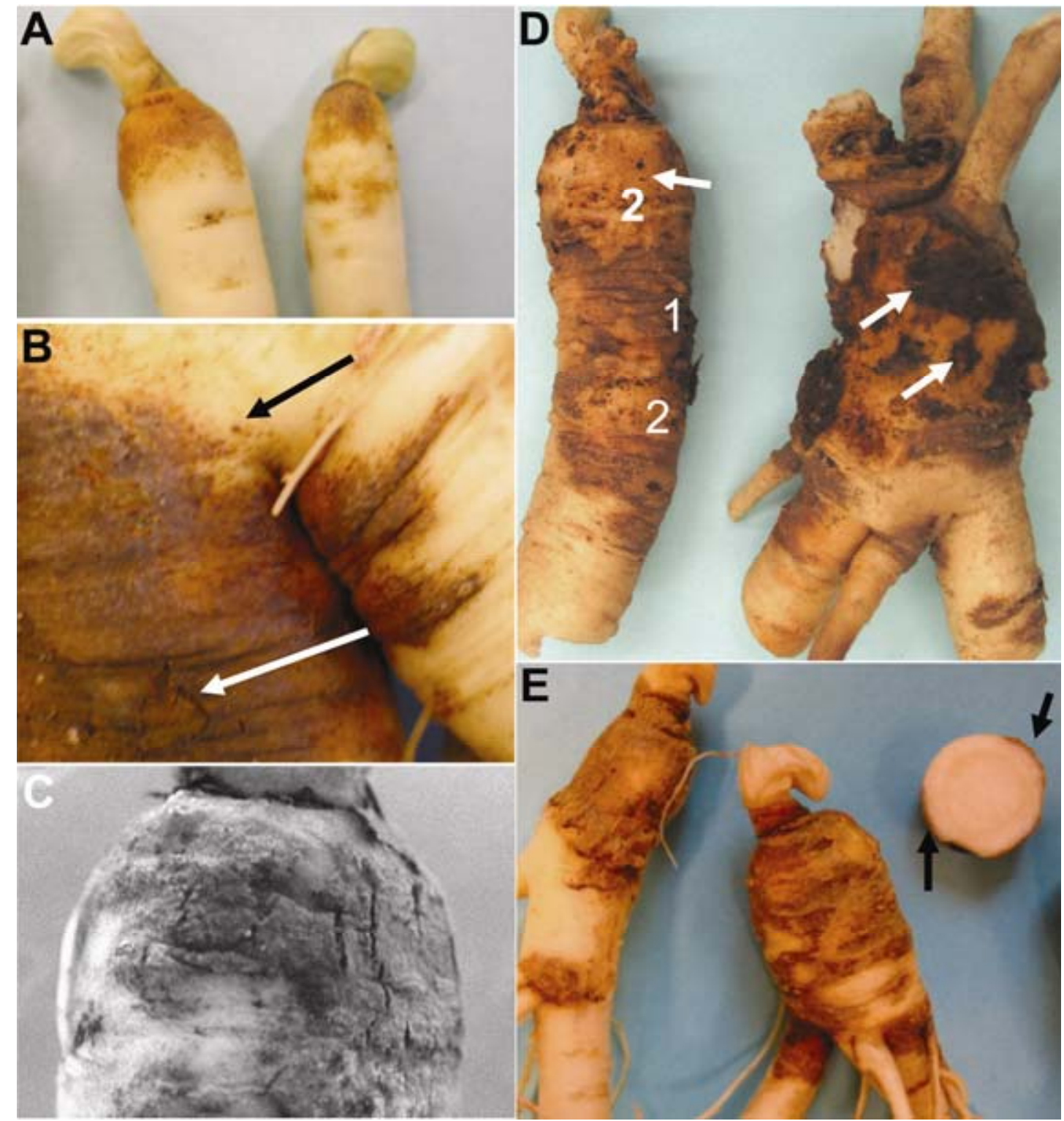

Fig. 1. Symptoms of rusted root observed on field-collected roots. A, Crown lesions on 1-year-old roots. B, Lesion on 5-year-old root showing diffuse margin with small "blister" lesions (black arrow) and initial rupturing of periderm (white arrow). The reddish-brown blister lesions represent the initial symptoms observed during disease development. C, Lesion with rupturing periderm tissue. D, Severe rusted root on 4-year-old roots. Arrows indicate blackened remnants of periderm; 1 indicates areas where periderm is discolored but intact and 2 indicates areas where periderm has been rotted away. E, Severe rusted root on 3-year-old roots. Cross-section illustrates limited penetration of lesion into root tissue. Arrows indicate location of lesions. 
albumin (BSA) $(1 \mu \mathrm{l}), 1 \mu \mathrm{l}$ of $10 \mathrm{mM}$ dNTP solution (Invitrogen, Burlington, ON), $0.4 \mu \mathrm{l}$ each of $50 \mathrm{mM}$ solutions of ITS4 and ITS5 oligonucleotides (Invitrogen), $1 \mu \mathrm{l}$ of JumpStart Taq DNA polymerase (Sigma-Aldrich, Oakville, $\mathrm{ON}$ ) at $2.5 \mathrm{U} / \mu \mathrm{l}$, and $5 \mu \mathrm{l}$ of extract. All reagents were obtained from Sigma-Aldrich unless otherwise indicated. Several runs were required to accommodate all samples. A positive control was provided by replacing the diseased tissue extract with $5 \mu$ of extract from a culture of C. destructans f. sp. panacis (28). In negative controls, extract was replaced with $5 \mu \mathrm{l}$ of sterile water. All PCR reactions were carried out using an Eppendorf Mastercycler (Brinkman, Mississauga, ON). PCR products were examined electrophoretically using $1.5 \%$ molecular grade agarose or $3 \%$ NuSieve GTG agarose
(Cambrex, East Rutherford, NJ) in $1 \times$ Tris-acetate-EDTA (TAE) buffer. Gels were run for $20 \mathrm{~min}$ at $8 \mathrm{~V} / \mathrm{cm}$, or $80 \mathrm{~min}$ at $5 \mathrm{~V} / \mathrm{cm}$. Representative bands present in samples from both diseased and healthy tissues were excised; DNA in the excised bands was extracted and purified using the Qiagen MinElute kit. Selected representative samples were cloned into plasmid vectors, as described below.

DNA extracts from V8 broth cultures of fungi isolated from roots (described below) with rusted root symptoms as well as fungi received from other culture collections (Tables 1 and 2) were obtained using DNeasy Plant Mini kits as described above. Extracts were frozen at $-20^{\circ} \mathrm{C}$ until use. These extracts also were amplified using the ITS5/ITS4 primer set. Selected PCR products

TABLE 1. Evaluation of specificity of oligonucleotide primers ${ }^{\mathrm{a}}$

\begin{tabular}{|c|c|c|c|c|c|c|}
\hline Taxon & $\begin{array}{c}\text { Reaction to } \\
\text { ONBCU3/ONBCL2 }\end{array}$ & $\begin{array}{l}\text { Product } \\
\text { size (bp) }\end{array}$ & $\begin{array}{l}\text { Reaction to } \\
\text { FEF1/FER1 }\end{array}$ & $\begin{array}{l}\text { Product } \\
\text { size (bp) }\end{array}$ & $\begin{array}{c}\text { Reaction to } \\
\text { FCO1F/FCO1R }\end{array}$ & $\begin{array}{l}\text { Product } \\
\text { size (bp) }\end{array}$ \\
\hline $\mathrm{RRD}^{\mathrm{b}}$ & ++ & 365 & - & $\ldots$ & - & $\ldots$ \\
\hline KAML $^{\mathrm{b}}$ & ++ & 365 & - & $\ldots$ & - & $\ldots$ \\
\hline Rhexocercosporidium carotae DAOM $226960^{c}$ & ++ & 365 & ND & $\ldots$ & ND & $\ldots$ \\
\hline Rhexocercosporidium sp. DSE48.1b $\mathrm{b}^{\mathrm{d}}$ & + & 365 & ND & $\ldots$ & - & $\ldots$ \\
\hline Euascomycete OOO15 & - & $\ldots$ & - & $\ldots$ & - & $\ldots$ \\
\hline Euascomycete OOO36 & - & $\ldots$ & ND & $\ldots$ & ND & $\ldots$ \\
\hline Trichoderma harzianum DAOM $190839^{f}$ & - & $\ldots$ & - & $\ldots$ & - & $\ldots$ \\
\hline Fusarium equiseti $\mathrm{FE} 87^{\mathrm{g}}$ & - & $\ldots$ & ++ & 400 & - & $\ldots$ \\
\hline Fusarium culmorum CD4B & - & $\ldots$ & - & $\ldots$ & ++ & 570 \\
\hline Fusarium solani $\mathrm{G} 14^{\mathrm{h}}$ & - & $\ldots$ & - & $\ldots$ & - & $\ldots$ \\
\hline Cylindrocarpon destructans f. sp. panacis CD1561 ${ }^{\mathrm{h}}$ & - & $\ldots$ & - & $\ldots$ & - & $\ldots$ \\
\hline Cylindrocarpon lucidum $\mathrm{FRI}^{\mathrm{i}}$ & - & $\ldots$ & - & $\ldots$ & - & $\ldots$ \\
\hline Cylindrocarpon cylindroides $\mathrm{CR}^{\mathrm{i}}$ & - & $\ldots$ & - & $\ldots$ & + & 650 \\
\hline Phialophora gregata $98 \mathrm{G} 1-3^{\mathrm{j}}$ & - & $\ldots$ & - & $\ldots$ & - & $\ldots$ \\
\hline Phialophora gregata $0478-105-3^{j}$ & - & $\ldots$ & ND & $\ldots$ & ND & $\ldots$ \\
\hline Rhizoctonia solani $895^{\mathrm{h}}$ & - & $\ldots$ & ND & $\ldots$ & ND & $\ldots$ \\
\hline
\end{tabular}

a Symbols: $++=$ strong band, $+=$ weak band, $-=$ no band and ND $=$ not determined.

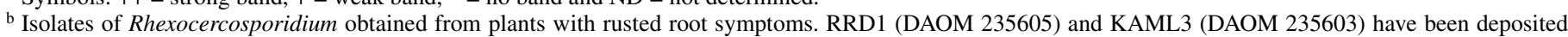
with the Canadian Collection of Fungal Cultures (CCFC), Ottawa, ON.

${ }^{c}$ Provided by C. Babcock.

d Provided by L. Wick.

e Provided by A. Osbourn.

${ }^{f}$ Provided by J. Traquair.

g Provided by R. Clear.

${ }^{\mathrm{h}}$ From culture collection of R. Reeleder.

i Provided by K. Dobinson.

j Provided by C. Grau.

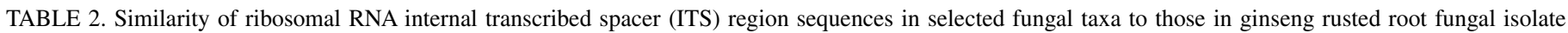
RRD1 (GenBank accession no. DQ249992)

\begin{tabular}{|c|c|c|c|c|c|c|c|}
\hline \multirow[b]{2}{*}{ Taxon or isolate } & \multirow{2}{*}{$\begin{array}{c}\text { GenBank } \\
\text { accession no. }^{\text {a }}\end{array}$} & \multicolumn{2}{|c|}{ ITS1 } & \multicolumn{2}{|c|}{$5.8 \mathrm{~S}$} & \multicolumn{2}{|c|}{ ITS2 } \\
\hline & & $\mathrm{SI}^{\mathrm{b}}$ & $\mathrm{Gaps}^{\mathrm{c}}$ & $\mathrm{SI}^{\mathrm{b}}$ & Gaps $^{\mathrm{c}}$ & $\mathrm{SI}^{\mathrm{b}}$ & Gaps $^{\mathrm{c}}$ \\
\hline $\mathrm{RRD}^{\mathrm{d}}$ & DQ249993 & 100.0 & 0 & 100.0 & 0 & 100.0 & 0 \\
\hline KAML $^{\text {d }}$ & DQ249995 & 100.0 & 0 & 100.0 & 0 & 100.0 & 0 \\
\hline F-ASH92d & DQ249994 & 100.0 & 0 & 100.0 & 0 & 100.0 & 0 \\
\hline Rhexocercosporidium carotae DAOM 226960 & AF487894 & 95.7 & 0 & 100.0 & 0 & 97.3 & 0 \\
\hline R. carotae DAOM 229433 & AF487895 & 95.7 & 0 & 100.0 & 0 & 97.3 & 0 \\
\hline Rhexocercosporidium sp. DSE48.1 $\mathrm{b}^{\mathrm{e}}$ & DQ303121 & 92.5 & 0 & 100.0 & 0 & 90.7 & 1 \\
\hline Euascomycete OOO15 ${ }^{\mathrm{f}}$ & $A J 246143$ & 89.3 & 6 & 100.0 & 0 & 98.6 & 0 \\
\hline Euascomycete $\mathrm{OOO} 36^{\mathrm{f}}$ & $A J 246144$ & 90.8 & 4 & 100.0 & 0 & 98.6 & 0 \\
\hline Phialophora gregata $\mathrm{P} 19$ & AY249070 & 83.5 & 2 & 100.0 & 0 & 94.0 & 1 \\
\hline P. gregata $\mathrm{P} 21$ & AY249071 & 83.5 & 2 & 100.0 & 0 & 94.0 & 1 \\
\hline 650-bp clone G14-6-2 & DQ275614 & 100.0 & 0 & 100.0 & 0 & 99.3 & 0 \\
\hline Trichoderma harzianum $^{\mathrm{h}}$ & AY625068 & 0 & $\ldots$ & 96.2 & 0 & 51.1 & 11 \\
\hline
\end{tabular}

a Accession numbers in italic were extracted from GenBank; all others were submitted to GenBank by the authors.

b Similarity index (SI) as calculated by the Martinez/Needleman-Wunsch Alignment (Megalign, DNASTAR).

c Number of gaps as determined by Martinez/Needleman-Wunsch Alignment (Megalign, DNASTAR).

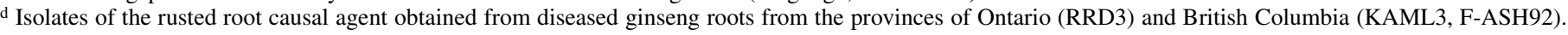

RRD1 (DAOM 235605) and KAML3 (DAOM 235603) have been deposited with the Canadian Collection of Fungal Cultures (CCFC), Ottawa, ON.

e Culture obtained from L. Wick, UFZ Centre for Environmental Research, Leipzig, Germany.

f Culture obtained from A. Osbourn, Sainsbury Laboratory, UK.

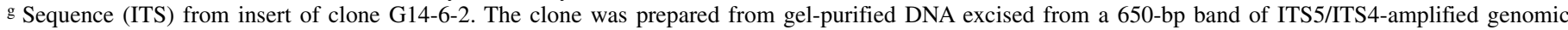
DNA extracted from roots with typical symptoms of rusted root.

${ }^{\text {h }}$ Hypocrea lixii strain NRRL 13019 (teleomorph). 
were sequenced using an Applied Biosystems 3730 Analyzer employing BigDye Terminator chemistry, with the ITS5 oligonucleotide.

Cloning and sequencing of DNA fragments in excised bands. Cloning of purified DNA obtained from 650-bp and other bands (see above) was carried out using the pGEM-T Easy (Promega Corp., Madison, WI) or TOPO-TA (Invitrogen) kits. Transformed Escherichia coli cells containing the correct inserts for either the 650- or 750-bp band were obtained. In all, 91 clones of the 650-bp fragment found in PCR products from 10 different fields were prepared. Then, 29 of the 650-bp clones and 12 of the 750 -bp clones were cultured and clonal DNA was extracted. DNA was sequenced as described above, using the T7 promoter primer. Representatives of less frequent fragments $(\approx 580$ to $600 \mathrm{bp}$ and 800 to $1,100 \mathrm{bp}$ ) also were cloned and sequenced.

Restriction digests of clonal DNA. DNA purified from representative clones of the 650-bp fragment also was subjected to restriction digests using EcoRI (Invitrogen). For each digestion, a 4- $\mu$ l DNA sample was added to $1.5 \mu \mathrm{l}$ of $10 \times$ REact buffer (Invitrogen), $0.25 \mu \mathrm{l}$ of EcoRI, and $9.5 \mu \mathrm{l}$ of autoclaved water. The mixtures were incubated at $37^{\circ} \mathrm{C}$ for $1 \mathrm{~h}$; then, digest products were electrophoresed on a $1.5 \%$ TAE gel at $5 \mathrm{~V} / \mathrm{cm}$ for $1 \mathrm{~h}$. Similar digests also were prepared using the enzymes HhaI (Invitrogen), HinFI (New England Biolabs, Pickering, ON), MboI (Invitrogen), and $\mathrm{MSeI}$ (New England Biolabs). For comparative purposes, digests also were prepared from ITS5/ITS4-amplified DNA obtained from pure cultures of fungi isolated from rusted root tissue (described below).

Isolation and pathogenicity testing of Rhexocercosporidium spp. The diseased roots in samples supplied by growers or collected from the Delhi research farm also were used in attempts to isolate fungal causal agents. Roots were washed again with tap water, and then cut cross-wise to produce sections of diseased tissue $\approx 1 \mathrm{~cm}$ in length. Root pieces were disinfested with $1 \%$ sodium hypochlorite for $1 \mathrm{~min}$, then washed twice with sterile water. Five 5-mm sections of disinfested tissue then were placed on MRBA medium (27), prepared by adding to 1 liter of distilled water: $1 \mathrm{~g}$ of $\mathrm{KH}_{2} \mathrm{PO}_{4}, 0.5 \mathrm{~g}$ of $\mathrm{MgSO}_{4} \cdot 7 \mathrm{H}_{2} \mathrm{O}, 50 \mathrm{mg}$ of rose bengal, $10 \mathrm{~g}$ of dextrose, $5 \mathrm{~g}$ of Bacto peptone (Difco Laboratories, Detroit), $15 \mathrm{~g}$ of Bacto agar, $30 \mathrm{mg}$ of streptomycin sulphate, $10 \mathrm{mg}$ of rifampicin (dissolved in $1 \mathrm{ml}$ of ethanol), $500 \mathrm{mg}$ of pentachloronitrobenzene, and $500 \mathrm{mg}$ of dicloran. Antibiotics and fungicides were added after autoclaving and cooling molten agar to $55^{\circ} \mathrm{C}$. Inoculated plates of MRBA were kept in darkness at room temperature $\left(22 \pm 2^{\circ} \mathrm{C}\right)$ for 2 days, then exposed to ambient light conditions for an additional 5 to 20 days. A slow-growing fungus with olivaceous gray mycelium (25) was commonly observed growing from diseased tissue. Single-spore cultures of this fungus were obtained and stored on V8 agar slants at room temperature. DNA extracts prepared from V8 broth cultures (described above) were subjected to PCR with the ITS5/ITS4 primer set, with conditions as described above. A 650-bp PCR product was obtained from cultures isolated from BC- and $\mathrm{ON}-$ grown diseased roots and the amplicons of representative isolates were sequenced as described above. Sequence data and conidium morphology were used to tentatively identify this fungus as a member of the genus Rhexocercosporidium.

Two methods were used to evaluate the pathogenicity of isolates of this fungus.

(i) Bare-root inoculation. Inoculum production. V8 broth (30 $\mathrm{ml}$ of supernatant from centrifuged V8 juice added to $970 \mathrm{ml}$ of deionized reverse-osmosis water) was added to petri dishes (10 $\mathrm{ml}$ per dish) and autoclaved. Broth was inoculated with a small block from a 2- to 3-week-old agar culture of a selected ginseng Rhexocercosporidium isolate (RRD1) and incubated at $16^{\circ} \mathrm{C}$ with a 12-h photoperiod. Two-week-old culture mats were washed with sterile water by vacuum filtration. Mats and the supporting filter paper then were cut into strips ( $\approx 5 \mathrm{~mm}$ wide by $2 \mathrm{~cm}$ long).
Inoculation. Healthy roots from field plots located at the Delhi research farm were washed clean of soil. Filter paper strips containing inoculum were placed on unwounded taproot, and held in place with a strip of autoclaved cheesecloth. The root then was wrapped in a clean, moistened paper towel and placed in a plastic bag. Bags were folded over to reduce moisture loss and placed in a stainless steel tray. Four roots were inoculated for each isolate tested; four additional control roots were treated similarly (autoclaved filter strips held in place with cheesecloth). Trays were placed in a large plastic bag, then transferred to incubators operating at $4,8,16$, and $24^{\circ} \mathrm{C}$ and $99 \%$ relative humidity (RH), without lights. Roots were examined after 4 or 8 weeks. Disease was assessed by recording the surface area of the lesion produced under the inoculum strip. Severities were compared using analysis of variance and Tukey's highly significant difference test (XLSTAT version 7.5). Three bare-root assays were carried out.

(ii) Pot assay. Inoculum production. Two methods of inoculum production were used. For one method, broth cultures were prepared as above. After 2 weeks, culture mats were scrapped from dishes using a rubber policeman and contents of 10 dishes were added to $100 \mathrm{ml}$ of sterile water and macerated using a sterilized blender. The volume was made up to $400 \mathrm{ml}$ of water. Macerate $(20 \mathrm{ml})$ was added to each pot containing field-grown roots as described below. For the second method of inoculum production, wheat seed (100 $\mathrm{g}$ of seed in a 500-ml Erlenmeyer flask) was soaked in excess water overnight, then autoclaved twice, on two successive days. Agar blocks from 2- to 3-week-old cultures of the fungus were added to the flasks. These were held at room temperature $\left(20 \pm 2^{\circ} \mathrm{C}\right)$ for 2 to 3 weeks. Colonized wheat seed $(10 \mathrm{~g})$ was added to each pot of transplanted ginseng seedlings or field-grown roots, as described below. Control pots received $10 \mathrm{~g}$ of noncolonized seed.

Inoculation: Field-grown roots (3 to 4 years old) were washed and diseased roots discarded. Roots were placed in 10 to $15 \mathrm{~cm}$ of clean bleach-disinfested pots (one root per $10-\mathrm{cm}$ pot or two roots per $15-\mathrm{cm}$ pot) partially filled with moistened pasteurized field soil, such that root crowns were just below the soil surface. Broth culture macerate inoculum was added by pouring around the base of the stem, after excavating and exposing $\approx 2 \mathrm{~cm}$ of root. Where macerate was used as the inoculum, a 1-cm layer of autoclaved vermiculite was added to the surface. Pots treated with macerate inoculum were placed in incubators $\left(16^{\circ} \mathrm{C}\right.$ at $99 \% \mathrm{RH}$, without lights) in a completely randomized design. Four pots each were prepared for the Rhexocercosporidium isolate and noninoculated controls. Pot weight was recorded and pots were reweighed every 2 weeks. Sufficient water was added to account for half of the weight difference. This allowed the soil to remain moist but below saturation. Roots were removed from pots and examined for disease severity after 10 weeks.

Two additional pot assays were carried out using greenhousegrown 5- to 6-month-old seedlings. Pots were prepared as above. Seedlings were transplanted into the pots and the wheat seed inoculum was distributed such that the colonized grains had contact with the roots. Additional soil was added to cover seed and roots. Control pots were prepared similarly using noncolonized seed. Pots receiving wheat seed inoculum were placed in growth chambers operating at $19^{\circ} \mathrm{C}$ (day) and $16^{\circ} \mathrm{C}$ (night) with a $12-\mathrm{h}$ photoperiod. Control pots were prepared similarly using noncolonized seed. After watering the soil, moisture sensors (Decagon $\mathrm{ECH}_{2} \mathrm{O}$ EC-10; Hoskins Scientific, Burlington, ON) were inserted into control pots. Sufficient water was added to pots as required to maintain soil moisture levels at 8 to $12 \%$. Roots were removed from pots and examined for disease severity after 10 to 11 weeks. Disease was assessed using a 1-to-7 scale, where 1 = symptomless root and $7=80 \%$ of the root covered with rusted root lesions. Three pot assays were carried out.

Design of oligonucleotide PCR primers specific for the 650bp fragment. Oligonucleotide primers specific for the DNA 
sequence obtained from the 650-bp band were designed (PrimerSelect, DNASTAR) using a consensus sequence (MegAlign, DNASTAR) from 10 representative 650-bp clones. Specificity of the resulting primer set ONBCU3 (5'-CAAAGAATAGACAGCGCCTCACAT-3')/ONBCL2 (5'-CCCCCGGAATACCAGAG$3^{\prime}$ ) was determined by assaying extracts prepared, as described above, from pure cultures of representative fungi (Table 1). PCR conditions were as follows. After an initial denaturing period of 2 min at $94^{\circ} \mathrm{C}$, template DNA was amplified for 35 cycles (denaturing at $94^{\circ} \mathrm{C}$ for $45 \mathrm{~s}$, annealing at $66^{\circ} \mathrm{C}$ for $45 \mathrm{~s}$, and extension at $72^{\circ} \mathrm{C}$ for $30 \mathrm{~s}$ ), followed by a final extension period of $10 \mathrm{~min}$ at $72^{\circ} \mathrm{C}$. Reactions then were cooled to $4^{\circ} \mathrm{C}$ prior to freezing at $-20^{\circ} \mathrm{C}$. Each $25-\mu \mathrm{l}$ reaction was composed of $16.2 \mu \mathrm{l}$ of sterile molecular-grade water, $2.5 \mu \mathrm{l}$ of $10 \times$ PCR buffer, $2.0 \mu \mathrm{l}$ of $25 \mathrm{mM} \mathrm{MgCl} 2,10 \mu \mathrm{g}$ of BSA $(0.5 \mu \mathrm{l}), 0.5 \mu \mathrm{l}$ of $10 \mathrm{mM}$ dNTP solution (Invitrogen), $0.2 \mu \mathrm{l}$ each of $50 \mathrm{mM}$ solutions of the ONBCU3 and ONBCL2 oligonucleotides (Invitrogen), $0.4 \mu \mathrm{l}$ of JumpStart Taq DNA polymerase at $2.5 \mathrm{U} / \mu \mathrm{l}$, and $2.5 \mu \mathrm{l}$ of diseased tissue extract. All reagents were obtained from SigmaAldrich unless otherwise indicated. PCR products were examined electrophoretically as described above.

Assays of DNA extracts from diseased tissue with specific PCR primers. The ONBCU3/ONBCL2 primer set (designed to amplify the 650-bp sequence found in extracts of diseased tissue) was used to assay extracts prepared from a second set of rusted root tissue samples, obtained during the summer and fall of 2005 and prepared using the DNeasy kits, as described above. Also included in the assays were samples from healthy-appearing regions on roots with symptoms of rusted root, samples from roots with symptoms of cylindrocarpon root rot (disappearing root rot) and rust spot (2), as well as samples from healthy-appearing ginseng roots collected from research plots at the Delhi farm. Amplification and electrophoresis conditions were as described above for evaluation of ONBCU3/ONBCL2 specificity. To further verify primer specificity, PCR products of 13 of those samples that yielded the expected 365-bp product were purified and sequenced using the ONBCU3 primer. Resulting sequence data were compared with those for an isolate (RRD1) of the predominant fungus isolated from rusted roots (tentatively described as Rhexocercosporidium), Rhexocercosporidium carotae DAOM 226960, and the consensus sequence for the ITS5/ITS4 650-bp band. Paired comparisons were made using the MartinezNeedleman-Wunsch method (MegAlign, DNASTAR).

For detection of Fusarium spp. in diseased tissue extracts, nested PCR assays were carried out. Amplification of extracted DNA was carried out first with the ITS5/ITS4 primer set, followed by a second round of amplification with oligonucleotide primers specific for Fusarium equiseti $(18)$ or F. culmorum $(9,19)$. The first round of PCR was carried out using the standard method for the ITS5/ITS4 primer set (described above). Reaction solution from the first round of PCR was used to provide template $(5 \mu \mathrm{l})$ for the second round. Reagent and oligonucleotide concentrations were as used for ONBCU3/ONBCL2 amplifications. Oligonucleotide primer sets FEF1 (5'-CATACCTATACGTTGCCTCG$3^{\prime}$ ) and FER1 (5'-TTACCAGTAACGAGGTGTATG-3') or FC01F (5'-ATGGTGAACTCGTCGTGGC-3') and FC01R (5'-CCCTTCTTACGCCAATCTCG-3') were used in separate reactions for detection of F. equiseti or F. culmorum, respectively. Amplification conditions used in the second round of PCR were initial denaturing for $60 \mathrm{~s}$ at $94^{\circ} \mathrm{C}$, followed by 25 cycles of denaturation at $94^{\circ} \mathrm{C}(60 \mathrm{~s})$, annealing at $58^{\circ} \mathrm{C}(30 \mathrm{~s})$, and extension at $72^{\circ} \mathrm{C}$ (60 s). After a final extension at $72^{\circ} \mathrm{C}$ for $7 \mathrm{~min}$, reactions were cooled to $4^{\circ} \mathrm{C}$. Extracts from pure cultures of representative isolates of these Fusarium spp. were used as positive controls. Sterile water was used as a negative control. Products of the second round of amplification were examined electrophoretically (5 V/cm for $45 \mathrm{~min}$ ) using a $1 \%$ agarose gel buffered with $1 \times$ TAE. To verify product specificity, bands from nine representative samples that were positive for $F$. equiseti were excised, purified (MinElute Gel Purification Kit, Qiagen), and sequenced. Although the primer sets used for detection of these species previously had been evaluated for specificity (9), additional evaluations were done here to ensure that Rhexocercosporidium spp. and similar fungi were not being amplified by these oligonucleotides (Table 1).

Effect of temperature on mycelial growth of Rhexocercosporidium spp. Single-spore cultures of putative Rhexocercosporidium isolates KAML3 (from diseased BC-grown roots), RRD1 (from diseased ON-grown roots), R. carotae (DAOM 226960), and Rhexocercosporidium sp. DSE48.1b (14) were compared with respect to radial growth on clarified dilute V8 agar. A sterilized cork-borer was used to cut 5-mm-diameter plugs in 2- to 3-week-old agar cultures of the isolates. Plugs were placed upside down at the center of fresh plates of each medium. Cultures were incubated in the dark at $4,8,16,24$, and $32( \pm 1)^{\circ} \mathrm{C}$ and radial growth was measured every 7 days for 21 days. Four replicate plates were prepared for each isolate and temperature combination and were arranged in a randomized complete block design. At 21 days, plates incubated at $32^{\circ} \mathrm{C}$ were transferred to $16^{\circ} \mathrm{C}$ and held for another 7 days to determine whether the observed lack of growth at $32^{\circ} \mathrm{C}$ was a consequence of the death of the culture at this temperature. Assays were carried out twice for each isolate. Nonlinear regression analysis (SigmaPlot version 9) was carried out to determine the response curve providing the best fit to radial growth data. The response curves were compared with soil temperature data (unpublished data) from ginseng agronomic experiments conducted at the Delhi research farm.

\section{RESULTS}

Fungal isolation from diseased root samples. Samples collected from fields in $\mathrm{BC}$ and $\mathrm{ON}$ had an identical range of symptoms (Fig. 1), corresponding to those described previously $(5,13)$. Samples collected by the authors from research plantings at the Delhi research farm also had similar symptoms. Delhi samples collected in midseason (July to August) generally had less severe symptoms and a lower incidence of infection than those collected in October. The periderm in midseason, although dark red or black in color at the center of the lesion, was largely intact; however, some rupturing was evident. Newer lesions consisted of a series of orange-red blisters, 1 to $2 \mathrm{~mm}$ in diameter. By October, the periderm in old lesions was mainly destroyed and absent except for blackened fragments that could be removed easily from the root surface. Younger lesions also were present, suggesting that lesions could be initiated throughout the growing season. These observations suggest that the disease cycle can be completed in a single growing season and continues through the summer months. Air drying of diseased roots resulted in a reduction of reddish orange coloration in lesions and a predominance of light brown to dark brown coloration.

One fungus was obtained consistently from those diseased tissue samples plated onto MRBA agar in 2004 and 2005. The fungus was slow growing with olivaceous gray (25) mycelium; 1 to 3 weeks of incubation often were required before there was sufficient colony growth for transfer to new plates. This fungus has been observed in rusted root samples from all three fields that were plated onto MRBA in 2004 and from all 10 fields plated onto MRBA in 2005. By contrast, no similar fungi were recovered from tissue of healthy roots plated onto MRBA. When transferred to clarified V8 agar, the colony was gray olivaceous (25) in color with a narrow white margin. Conidia morphology (cylindrical, with a basal truncate scar) and colony characteristics, in combination with sequence data (described below), suggest that this fungus is a species of Rhexocercosporidium.

Molecular characterization of ITS PCR products of diseased tissue extracts. The ITS5/ITS4 amplification of DNA extracted from diseased tissue resulted in two major products, one 
represented by a band at $\approx 750$ bp and the second represented by a band at $\approx 650 \mathrm{bp}$ (Fig. 2A and B). Extracts from 25 of 27 diseasefree roots yielded only the 750-bp band; two of these apparently healthy roots yielded both the 750-bp and either the 650-bp band or a smaller band $(\approx 600 \mathrm{bp})$. When samples of healthy-appearing peridermal tissue on otherwise rusted roots were excised and extracted, 1 of 10 samples yielded the 650 -bp band as well as the 750-bp band. By contrast, both the 650- and 750-bp bands were visible in all 49 samples of rusted root tissue from plants collected at five locations in $\mathrm{BC}$ and five locations in $\mathrm{ON}$ during fall 2004 and spring 2005 (Table 3). Samples of these bands were excised, cloned, and sequenced (described below).

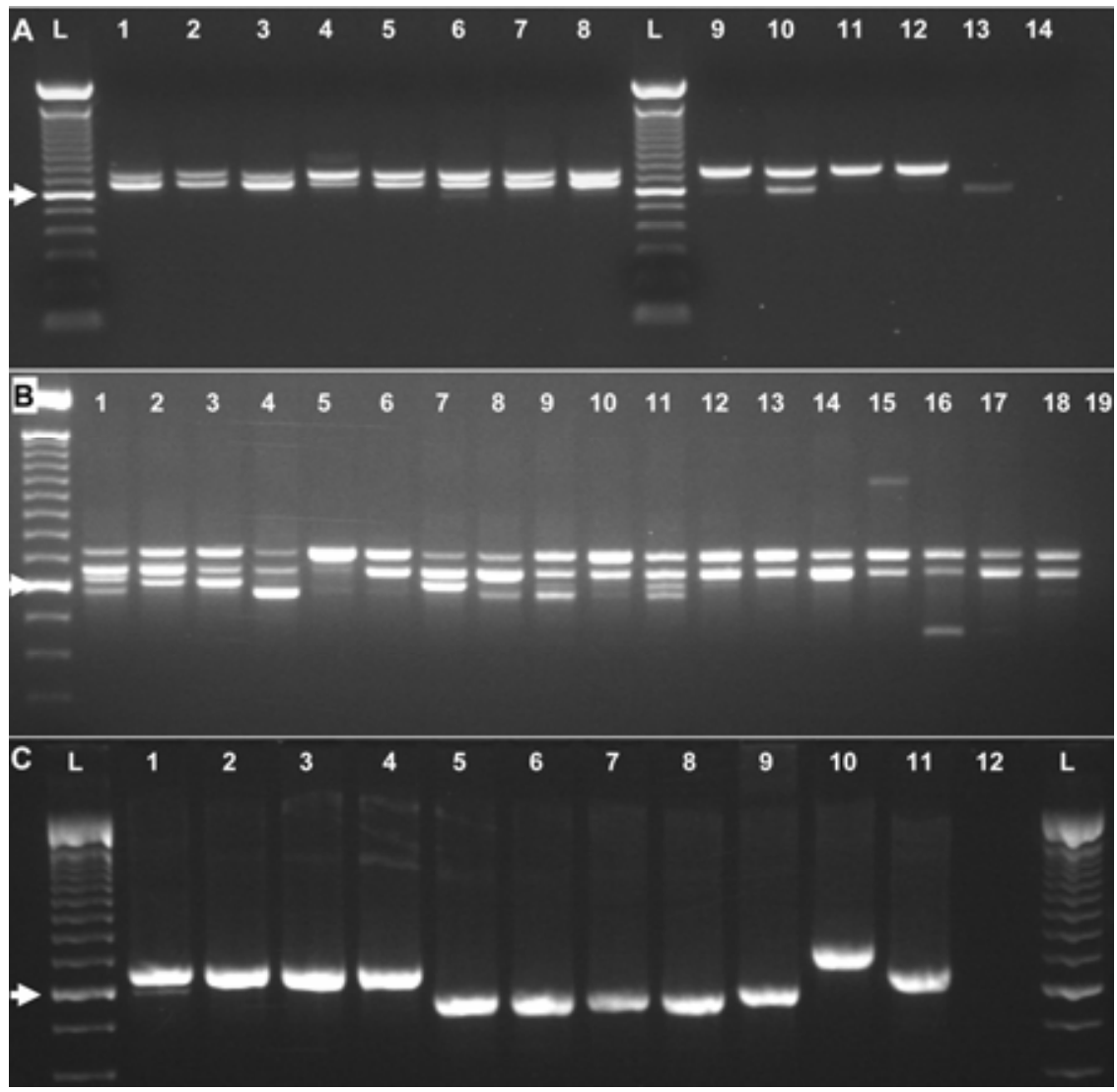

Fig. 2. Products of internal transcribed spacer (ITS)5/ITS4 amplification of rusted root extracts. A, Rusted root tissue extracts from field-collected roots. L, 100-bp ladder (arrow indicates location of 600-bp band); lanes 1 to 8 represent polymerase chain reaction products from rusted root tissue; lanes 9 to 12 represent tissue from healthy-appearing roots; lane 13, Cylindrocarpon destructans CD1561-positive amplification control; lane 14, negative water control. B, Rusted root tissue extracts from field-collected roots. Lanes 1 to 11 represent samples from British Columbia field, lane 5 has a weak 650-bp band; lanes 12 to 18 represent samples from an Ontario field. Lane 19, water control. C, Fungal pure culture extracts. Lanes 1 to 4, 650-bp products for ginseng Rhexocercosporidium isolates RRD1, RRD3, KAML3, and F-ASH92, respectively; lanes 5 to 6, isolates FE87 and FE88 of Fusarium equiseti; lanes 7 to 8, isolates CD4B and CD9A of F. culmorum; lane 9, F. solani G14; lane 10, Rhizoctonia solani 895; lane 11, Trichoderma harzianum DAOM 190839; lane 12, water control.

TABLE 3. Distribution of Rhexocercosporidium in field-collected ginseng roots

\begin{tabular}{|c|c|c|c|c|c|c|c|c|c|c|}
\hline \multirow[b]{3}{*}{ Primer, region ${ }^{\mathrm{d}}$} & \multicolumn{10}{|c|}{ Root symptom category ${ }^{\mathrm{a}}$} \\
\hline & \multicolumn{2}{|c|}{ Rusted root } & \multicolumn{2}{|c|}{ Symptomless region $^{\mathrm{b}}$} & \multicolumn{2}{|c|}{ Symptomless root } & \multicolumn{2}{|c|}{ Cylindrocarpon root $\operatorname{rot}^{\mathrm{c}}$} & \multicolumn{2}{|c|}{ Rust spot ${ }^{\mathrm{c}}$} \\
\hline & $N$ & Pos $(\%)$ & $N$ & $\operatorname{Pos}(\%)$ & $N$ & Pos $(\%)$ & $N$ & Pos $(\%)$ & $N$ & Pos $(\%)$ \\
\hline \multicolumn{11}{|c|}{ ITS5/ITS4 (650-bp band) } \\
\hline $\mathrm{ON}$ & 25 & 100 & 4 & 25.0 & 27 & 7.4 & NA & NA & NA & NA \\
\hline $\mathrm{BC}$ & 24 & 100 & 6 & 0 & 0 & 0 & NA & NA & NA & NA \\
\hline Total & 49 & 100 & 10 & 10.0 & 27 & 7.4 & NA & NA & NA & NA \\
\hline \multicolumn{11}{|c|}{ ONBCU3/ONBCL2 ${ }^{\mathrm{f}}$} \\
\hline $\mathrm{ON}$ & 48 & 95.8 & 2 & 0 & 5 & 0 & 6 & 16.7 & 4 & 0 \\
\hline $\mathrm{BC}$ & 24 & 87.5 & 8 & 37.5 & 0 & 0 & NA & NA & NA & NA \\
\hline Total & 72 & 93.1 & 10 & 30.0 & 5 & 0 & 6 & 16.7 & 4 & 0 \\
\hline
\end{tabular}

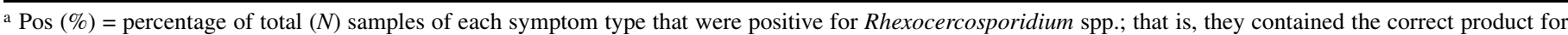
Rhexocercosporidium (650 bp for internal transcribed spacer (ITS)5/ITS4 polymerase chain reaction (PCR) and 365 bp for ONBCU3/ONBCL2, as determined by post-PCR electrophoresis; and NA = not applicable.

b Symptomless region of rusted root.

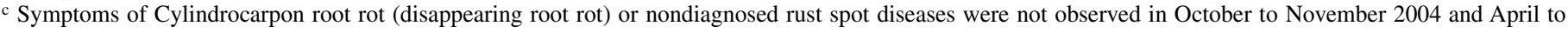
May 2005 samples.

d Oligonucleotide primer set used for Ontario (ON) and British Columbia (BC).

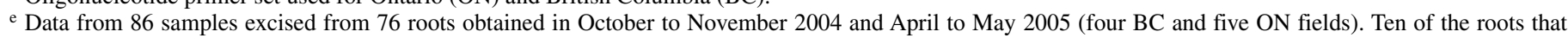
provided rusted root samples also provided symptomless region of rusted root samples.

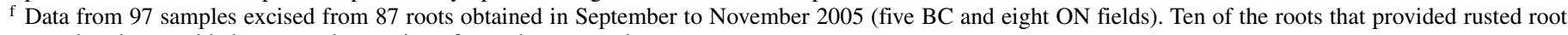
samples also provided symptomless region of rusted root samples. 
A number of other bands, ranging in size from 580 to 600 or 800 to $1,100 \mathrm{bp}$, were present in some diseased tissue samples (Fig. 2A and B). These bands varied in occurrence from field to field; in diseased tissue extracts from some $\mathrm{ON}$ and $\mathrm{BC}$ fields, these bands were absent; yet, in samples from other fields, these bands were present in all extracts. On average, $36 \%$ of $\mathrm{ON}$ samples and $75 \%$ of $\mathrm{BC}$ samples yielded these extra bands. Samples of these less frequent bands were excised, purified, and sequenced. Bands of 580 to $600 \mathrm{bp}$ were found to have a high (97 to $100 \%$ ) similarity to GenBank sequence data for a Cylindrocarpon sp., F. oxysporum, and F. solani. These latter bands provided 75 and $100 \%$ of the non-650- and non-750-bp bands in the $\mathrm{ON}$ and $\mathrm{BC}$ samples, respectively. Bands of 800 to $1,100 \mathrm{bp}$ were most closely associated (91 to $92 \%$ ) to GenBank sequences of bacterial and fungal-feeding nematode genera. The inconsistent detection of these latter bands (580 to 600 and 800 to 1,100 bp) in amplified diseased tissue extracts suggests that the organisms represented by these sequences are not causal agents of rusted root.

Cloning and sequencing of DNA fragments in excised 650- and 750-bp bands. DNA from clones of the 750-bp fragment was determined, after BLAST (1) analysis, to belong to the Panax host; therefore, this fragment was not of interest with respect to the etiology of the disease. A representative sequence (DQ249991) has been deposited in GenBank.

DNA inserts from 29 clones prepared from 650-bp bands observed in ITS5/ITS4 PCR products were sequenced. Each clone represented a different 650-bp band obtained from diseased samples from eight locations (four from BC and four from $\mathrm{ON}$ ). When sequences of the ITS and 5.8S regions of a random selection of 13 clones were aligned (MegAlign), the clones were found to be identical to one another within the 5.8S and ITS2 regions and differ by no more than 1 to 2 nucleotides in the ITS1 region. These differences were due to nonresolved " $\mathrm{N}$ " nucleotides. These data suggest that a single organism is responsible for the 650-bp band. A representative clonal DNA sequence (DQ275614) of the 650-bp band has been deposited in GenBank.

Restriction digests of clonal DNA from 650-bp bands. EcoRI digests of the 650-bp fragment showed a consistent pattern in 89 of 91 samples assayed, suggesting that the 650-bp band represented a single taxon that was consistently present in the diseased tissue (Fig. 3A). A subset of samples also was digested with additional restriction enzymes; again, the samples produced similar patterns (Fig. 3B). These results further support the conclusion that a single organism was responsible for the 650-bp band in amplified diseased tissue extracts.

Molecular characterization of ITS PCR products of fungal culture extracts. DNA samples extracted from cultures (isolates RRD1 and KAML3) of the predominant fungus isolated from rusted roots on MRBA (tentatively identified as Rhexocercosporidium sp.), R. carotae, Cylindrocarpon spp., Fusarium spp., Trichoderma harzianum, and Rhizoctonia solani were amplified using the ITS5/ITS4 primer set. The rusted root isolates and
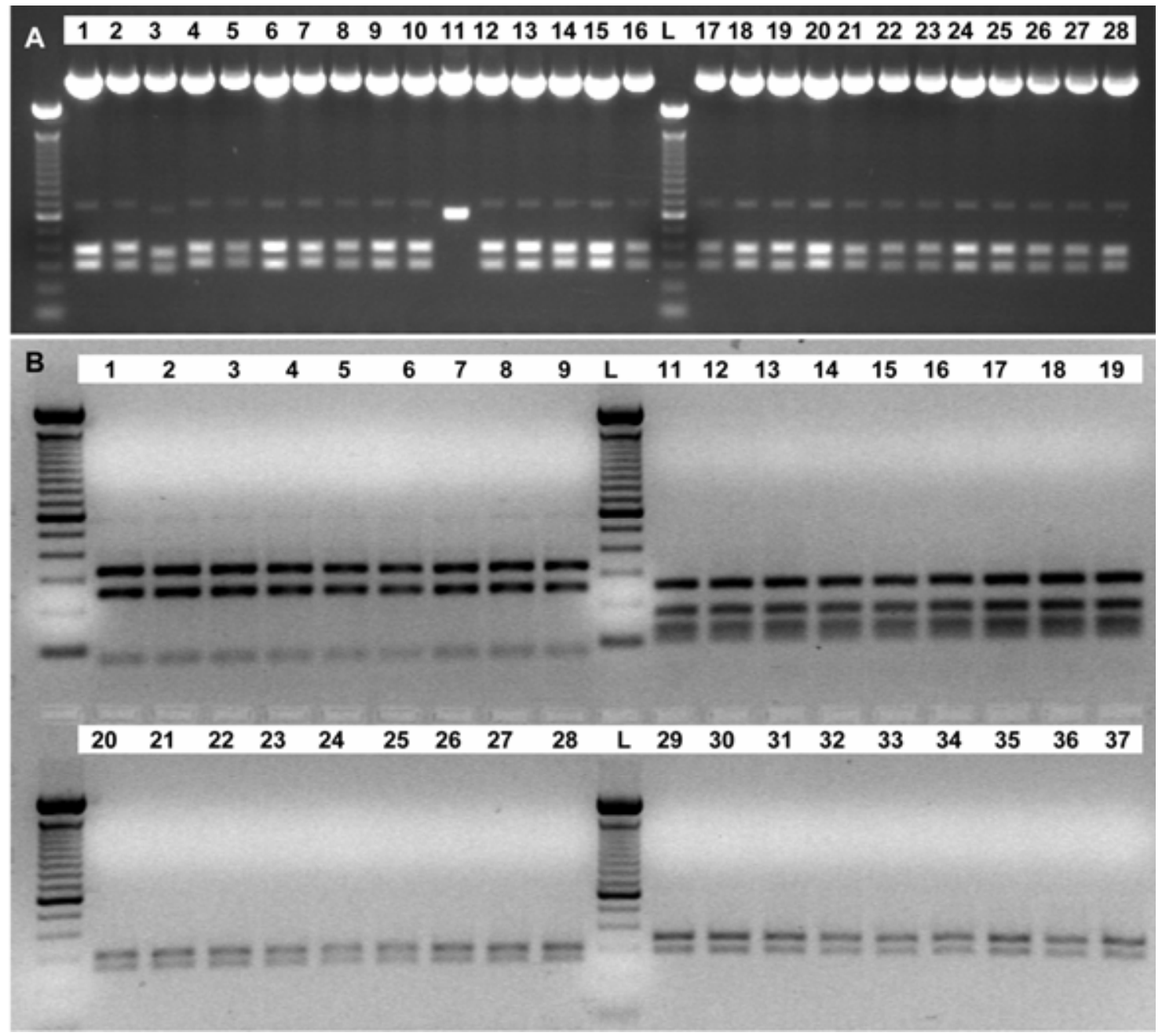

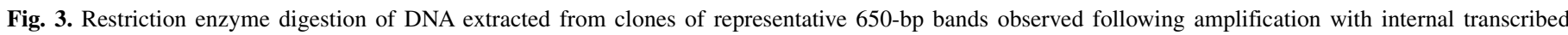

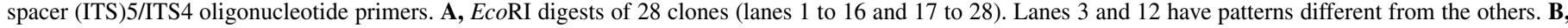

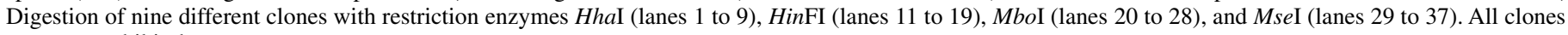
appear to exhibit the same patterns. 
Rhexocercosporidium carotae produced 650-bp products; Rhizoctonia solani yielded a 700-bp product (Fig. 2C). Most other fungi tested produced products of distinctly different sizes; only $T$. harzianum produced a product of similar size. Restriction digests of the ginseng Rhexocercosporidium isolates RRD1 and RRD3 resulted in patterns identical to those found in digests of the 650-bp bands.

Comparison of sequence data of the 650-bp product in amplified diseased tissue extracts to fungal sequences. BLAST analyses showed that sequences of 29 individual 650-bp DNA clones had a high degree of similarity (mean 96.7, range 93 to $97 \%$ ) to sequences of isolates of Rhexocercosporidium carotae (AF487894 and AF487895). An "uncultured mycorrhizal" fungus (AY634148) and a euascomycete isolated from oat roots (AJ24613) had similar percent identity scores, but alignment of these with clonal DNA required three to six gap insertions.

A consensus alignment of 10 of the 650-bp clones, selected at random from three $\mathrm{ON}$ and three $\mathrm{BC}$ fields, was compared with sequences from four fungal isolates obtained from rusted root tissue. These putative Rhexocercosporidium isolates were typical of those arising from rusted root tissue on MRBA plates. A comparison of ITS DNA regions in the consensus sequence with those found in cultures of the putative Rhexocercosporidium cultures RRD1, RRD3, F-ASH92, and KAML3 showed that they were identical over the ITS1, 5.8S, and ITS2 regions (Table 2). Sequences (DQ24992-DQ24995) of these cultures have been deposited in GenBank. When these were aligned with the same region of DNA from Rhexocercosporidium carotae (AF487895), they were found to be identical within the 5.8S region and differ by seven to eight nucleotides within the ITS1 region. Pairwise sequence comparisons were made between a representative diseased-tissue 650-bp clone sequence, similar fungal GenBank sequences, and sequences from the putative Rhexocercosporidium isolates obtained from rusted root tissue (Table 2). These comparisons strongly suggest that sequences of the 650-bp clones and the putative Rhexocercosporidium rusted root isolates are identical and that the rusted root isolates are closely related to $R$. carotae. T. harzianum was not similar to ginseng Rhexocercosporidium isolates, or to the representative 650-bp clone (Table 2). This suggests that $T$. harzianum made little or no contribution to the 650-bp fragments observed following amplification of rusted root extracts with the ITS5/ITS4 primer set.

Design and use of specific primer sets. Using consensus sequence data from the 650-bp clones, oligonucleotide primers were designed to amplify Rhexocercosporidium DNA in diseased roots. Of the cultures tested, these primers (ONBCU3/ONBCL2) were shown to amplify only Rhexocercosporidium spp. (Table 1). When these primers and primers specific for Fusarium spp. were used to assay diseased tissue extracts (from root samples obtained in fall 2005) for these fungi, only a Rhexocercosporidium sp. was consistently detected (Table 3). A Rhexocercosporidium sp. was detected in 67 of $72(93 \%)$ diseased tissue samples assayed but was not detected in 5 samples of healthy-appearing roots (Fig. 4A). The frequency of detection of Rhexocercosporidium spp. in diseased tissue was somewhat higher in ON samples (96\%) than in BC samples (88\%). We detected the fungus in all symptom types, including the initial small blister lesions and severely diseased roots. Of samples taken from healthy-appearing regions of rusted roots, $30 \%$ tested positive for Rhexocercosporidium spp. When PCR products for 13 selected extract samples (representing nine different fields) were sequenced and resulting sequences submitted to GenBank, products from amplification with the ONBCU3/ONBCL2 primer set were 97\% similar to sequence data for $R$. carotae. When pairwise comparisons were made between sequence data from these ONBCU3/ONBCL2 products from diseased tissue samples and ITS region sequences from ginseng Rhexocercosporidium isolate RRD1, they were found to be 99 to $100 \%$ similar to the fungus. These data strongly suggest that, in these samples, the ONBCU3/ONBCL2 primer set is amplifying the Rhexocercosporidium sp. associated with rusted root tissue, but not other fungi, and that this fungus is closely associated with the symptoms of rusted root.

By contrast, only 12 of 41 diseased tissue samples assayed were positive for $F$. equiseti and only 2 of 41 disease samples were positive for $F$. culmorum. These samples were chosen for analysis by randomly selecting three $\mathrm{BC}$ and three $\mathrm{ON}$ locations. When results for each location were examined, the incidence of F. equiseti was found to vary (Fig. 4B) from 0 to $100 \%$ among the $\mathrm{BC}$ locations and from 12 to $16 \%$ among the ON locations. F. culmorum was not detected in roots from the three ON loca-

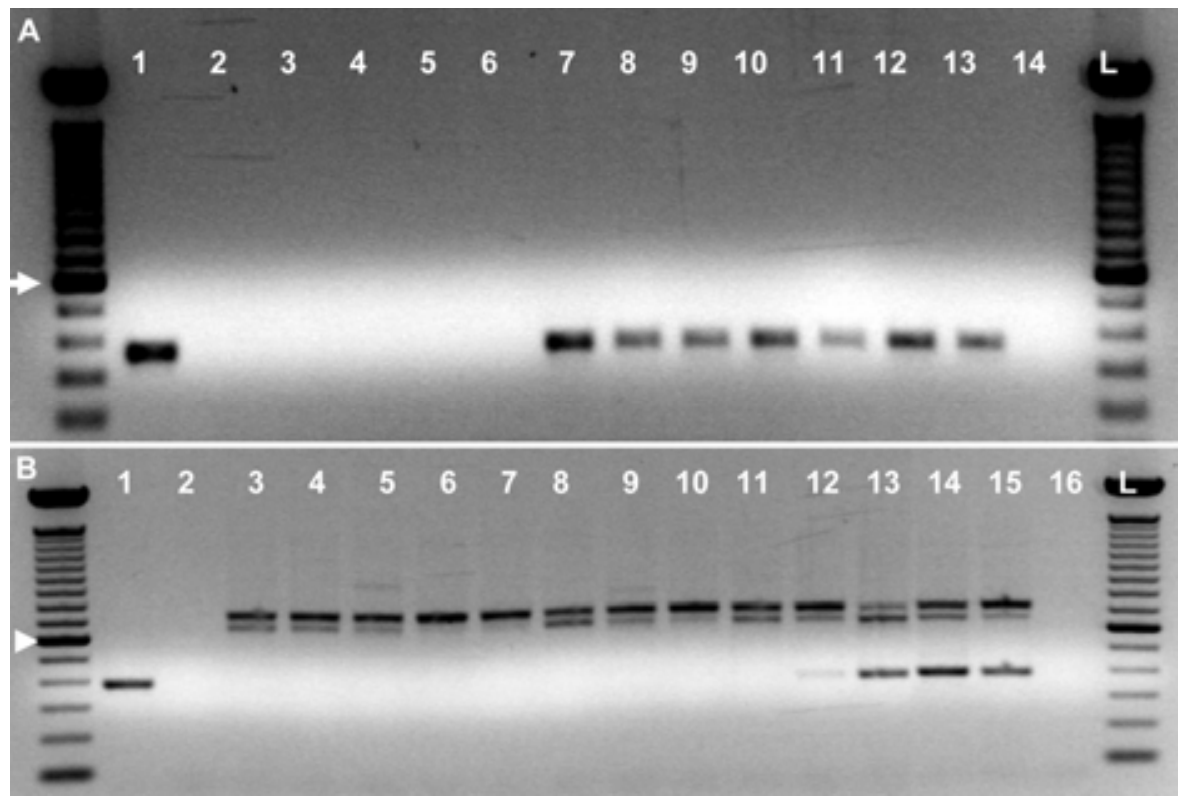

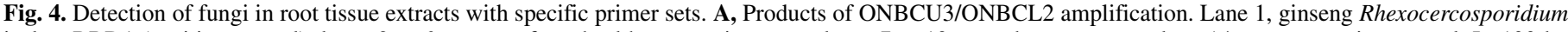

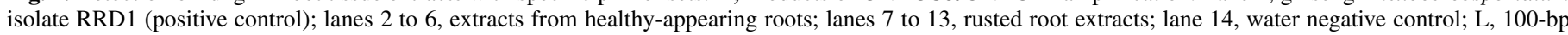

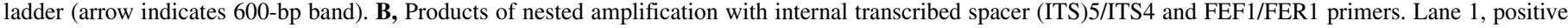

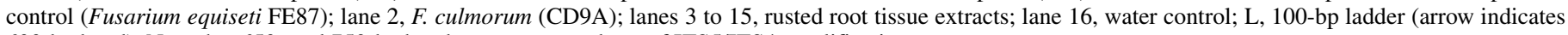
$600-$ bp band). Note that 650- and 750-bp bands represent products of ITS5/ITS4 amplification. 
tions and the incidence varied from 0 to $25 \%$ in the three $\mathrm{BC}$ locations. Assays with the $F$. equiseti-specific primer set also were carried out on frozen samples from the fall 2004-spring 2005 survey. Of $15 \mathrm{ON}$ samples tested, only 1 (6.7\%) was positive for F. equiseti; 5 of $18 \mathrm{BC}$ samples were positive (27.8\%). Overall, $17.2 \%$ of these latter samples were positive for F. equiseti. These data suggest that, compared with Rhexocercosporidium spp., these Fusarium spp. are only weakly associated with rusted root symptoms. The primer sets for these two Fusarium spp. were found to be adequately specific (Table 1). The F. culmorum primer set weakly amplified an isolate of $C$. cylindroides; however, the product size was distinct from that of $F$. culmorum and no products matching that of $C$. cylindroides were found in these assays. Therefore, it is unlikely that this would interfere with detection of F. culmorum. Nine PCR products obtained by amplifying rusted root tissue extracts with the $F$. equiseti primers were purified and sequenced. BLAST analysis showed that these products were 99 to $100 \%$ similar to $F$. equiseti sequences in GenBank. This further supports the use of this primer set for detection of F. equiseti.

Tissue samples from roots with symptoms of disappearing root rot $(C$. destructans $\mathrm{f}$. sp. panacis) and nondiagnosed rust symptoms (rust spot) (7) were assayed using the Rhexocercosporidium primer set. Only one of six disappearing root rot samples were positive for Rhexocercosporidium spp.; this provides further evidence that a Rhexocercosporidium sp. rarely is a secondary invader of diseased tissue and that its presence in rusted root tissue is due to its role as a causal agent. $C$. destructans f. sp. panacis was isolated from disappearing root rot samples that were plated onto MRBA. Similarly, we did not detect a Rhexocercosporidium sp. in the rust spot tissue (Table 2).

Effects of temperature on radial growth. Two isolates of the ginseng Rhexocercosporidium sp. obtained from symptomatic roots collected in $\mathrm{ON}$ and $\mathrm{BC}$ were compared with $R$. carotae DAOM 226960 (29), previously isolated from carrot, and Rhexocercosporidium sp. DSE48.1b (14), isolated from soil. The ginseng isolates were found to have similar responses to temperature when cultured on V8 agar (Fig. 5). Maximum growth occurred in cultures incubated at $16^{\circ} \mathrm{C}$; data were fitted to a Weibull fiveparameter curve (adj. $\left.R^{2}=0.99\right)$ and the resulting equation predicted maximum growth at $18.2^{\circ} \mathrm{C}$ for isolate RRD1 (Fig. 5) and $18.6^{\circ} \mathrm{C}$ for isolate KAML3 (not shown). Average growth per day $\left(16^{\circ} \mathrm{C}\right)$ for these two isolates was $1.61 \pm 0.03 \mathrm{~mm}( \pm$ standard error). $R$. carotae grew more slowly $(0.69 \pm 0.03 \mathrm{~mm} /$ day at $16^{\circ} \mathrm{C}$ ) with a predicted maximum growth (Weibull curve) at $16.6^{\circ} \mathrm{C}$. Isolate DSE48.1b was intermediate in terms of growth rate $\left(1.15 \pm 0.02 \mathrm{~mm} /\right.$ day at $\left.16^{\circ} \mathrm{C}\right)$ but had a higher predicted growth maximum of $19.4^{\circ} \mathrm{C}$. Although all isolates tested grew at $4^{\circ} \mathrm{C}$, none grew at $32^{\circ} \mathrm{C}$; no growth occurred when $32^{\circ} \mathrm{C}$ plates were transferred to $16^{\circ} \mathrm{C}$ and incubated for 1 week.

Soil temperature data (1999 to 2001) for conventional strawmulched raised ginseng beds located at the Delhi research farm were examined. Average monthly temperatures from May to September at a soil depth of $5 \mathrm{~cm}$ were determined and found to begin at $\approx 5^{\circ} \mathrm{C}$ in May, peak at $\approx 19^{\circ} \mathrm{C}$ in July, then fall to $\approx 15^{\circ} \mathrm{C}$ in September. Thus, growing-season soil temperatures would appear to be suitable for pathogen growth and disease development. Soil temperature data for mulched ginseng beds in BC were not available; however, historic weather records (11) show that air temperatures in the two regions (represented by Delhi, ON, and Summerland, BC) are similar; thus, soil temperatures under mulch are likely to be comparable.

Pathogenicity assays. Symptoms of rusted root were observed on inoculated roots in bare-root assays at $16^{\circ} \mathrm{C}$ and in pot assays at 16 to $19^{\circ} \mathrm{C}$ (Fig. 6). Although large portions of the root became diseased in some assays, the lesions did not penetrate deeply into the root. No symptoms of the disease appeared on control roots. In bare root assays, disease symptoms developed more quickly at $16^{\circ} \mathrm{C}$. After 8 weeks, disease severity was significantly $(P=0.05)$ more severe, in two of three assays, at 16 and $8^{\circ} \mathrm{C}$ than at 4 or $24^{\circ} \mathrm{C}$; in the third assay, the $16^{\circ} \mathrm{C}$ treatment had significantly $(P=$ $0.05)$ greater disease severity than other temperatures (Fig. 6D). Symptoms observed on inoculated roots (Fig. 6) were similar to those observed on roots collected from the field (Fig. 1). The initial small red-brown blister lesions were observed within 4 weeks of inoculation in bare-root assays. Large, coalesced lesions, red-brown to dark red or black in color, were observed by 8 to 10 weeks in both bare-root and pot assays. Initial rupturing of diseased periderm tissue was observed at this time in both types of assay.

In the three-pot assays, mean disease severities per pot (after 10 to 11 weeks) ranged from 4.6 to 6.2 (1-to-7 scale) in inoculated pots and were significantly $((P=0.05)$ less in control pots (1.0 to 1.2$)$. Disease symptoms reflected those observed in the field (Fig. 6). The fungus could be recovered from diseased tissue using MRBA and detected in tissue using the PCR method described here.

\section{DISCUSSION}

Symptoms on roots supplied by growers (54\% of fields) and on those collected by the investigators ( $46 \%$ of fields) were similar to those previously reported $(5,13,22)$. Thus, the samples can be said to be representative of this disease, which appears to be widespread in ginseng-growing regions in North America. Although a number of different fungi have been isolated from rusted root lesions, our data suggest strongly that a single organism is responsible for the disease in the major growing regions of North America. Cloning, sequencing, and restriction enzyme digestion of the 650-bp fragment that was observed in all of the rusted root tissue samples confirmed that a single fungus, likely a Rhexocercosporidium sp., was responsible for the 650-bp band. Sequence data were used to design specific primers for Rhexocercosporidium spp. When additional separate sets of root samples subsequently were examined using these new primers, the Rhexocercosporidium fungus was detected in $96 \%$ of ON samples and $88 \%$ of BC samples.

Culturing diseased tissue on a medium (MRBA) that suppressed fast-growing fungi (27) allowed us to isolate the fungus from diseased roots. We found that amplification of DNA extracts of this fungus with the ITS5/ITS4 primer set yielded a 650-bp product identical to that found in amplified rusted root extracts. Sequence analysis and cultural characteristics showed that the

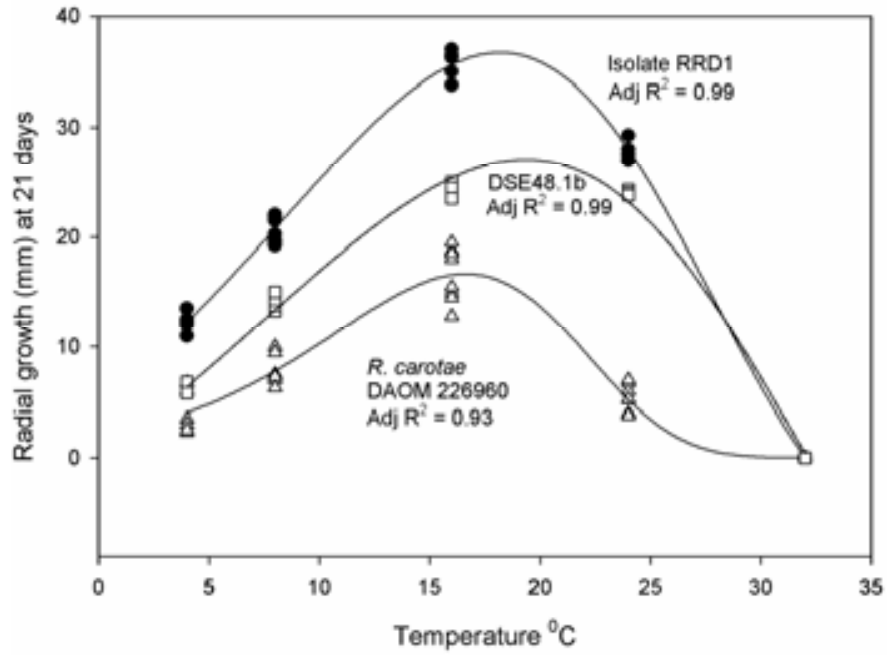

Fig. 5. Effect of temperature on radial growth of isolates of Rhexocercosporidium spp. on V8 agar after 21 days of incubation. Combined data of two experiments $(n=8)$ are shown. 
fungus is likely a species of Rhexocercosporidium, closely related to $R$. carotae, a pathogen of carrots previously identified as Acrothecium carotae $(3,29)$. Sequencing of PCR products obtained following amplification of diseased extracts with the Rhexocerco- sporidium sp.-specific primer set confirmed that DNA of the ginseng Rhexocercosporidium sp. was being amplified. These data support the use of this primer set in assessing the frequency of Rhexocercosporidium spp. in rusted root tissue. Further, we
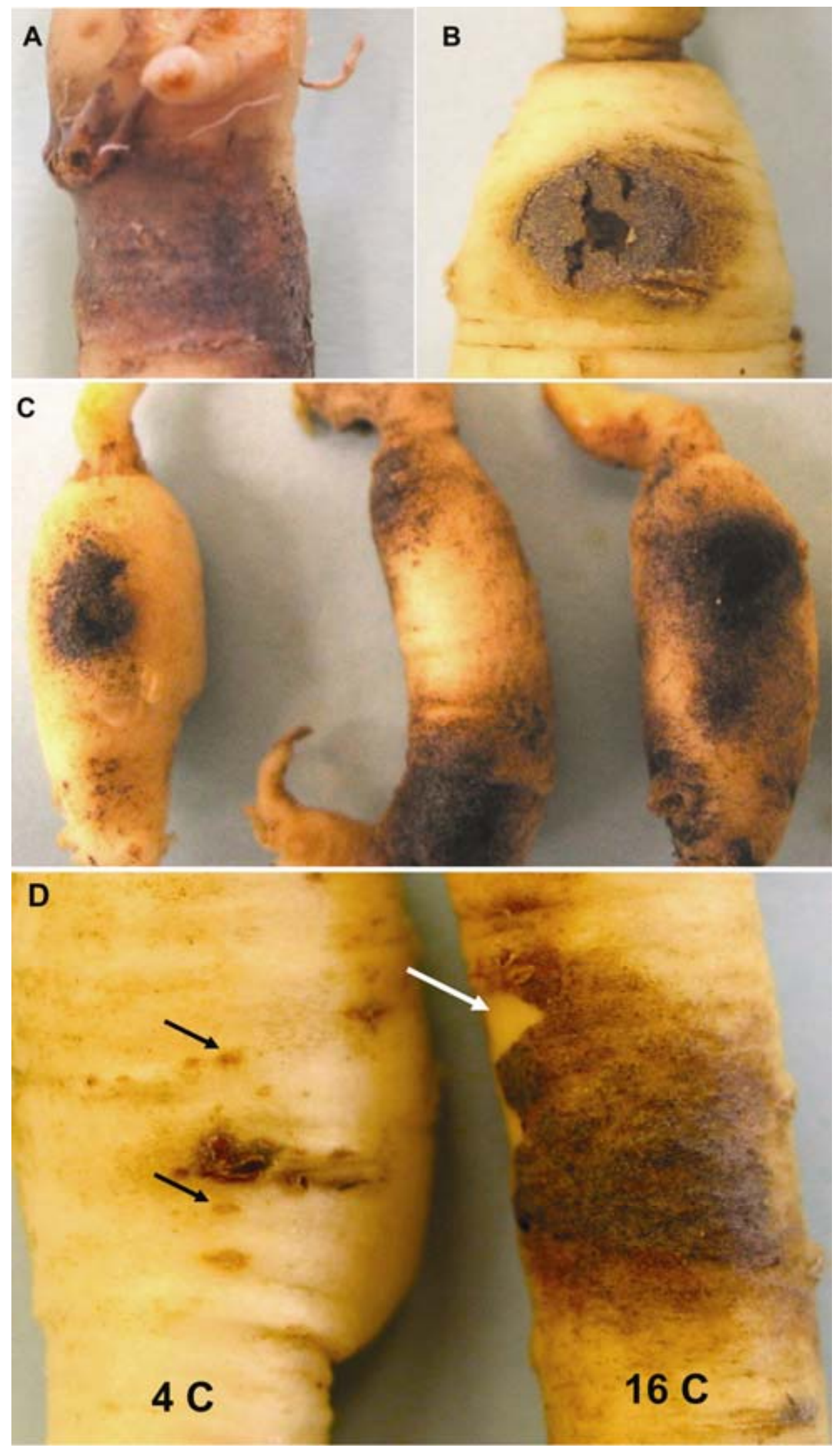

Fig. 6. Symptoms observed on roots inoculated with a ginseng Rhexocercosporidium isolate (RRD1). A, Bare-root inoculation after 8 weeks at $16^{\circ} \mathrm{C}$. B, Pot assay (macerate inoculum) after 10 weeks (note rupturing periderm). C, Pot assay (infested seed inoculum) after 10 weeks. Note small "blister" lesions near margin of larger lesions. D, Close-up of bare-root inoculation showing differences in disease development at 4 and $16^{\circ} \mathrm{C}$. Note the small blister lesions (black arrows) which are the earliest stages of infection. These coalesce as they expand. White arrow indicates removal of diseased periderm to show underlying healthy tissue. 
suggest that, for such slow-growing fungi, PCR technologies are more suitable for detection in etiology or epidemiology studies than agar media. Although media such as MRBA can improve detection, they often will be less sensitive than molecular technologies in detecting targets in complex environmental samples.

In pathogenicity tests, isolates of the ginseng Rhexocercosporidium sp. reproduced the symptoms of the disease. The initial symptoms observed in pathogenicity bioassays (small pinpoint reddish orange lesions) are often seen on the outer edge of lesions observed on field-collected roots. These expand and coalesce, resulting in the ruptured periderm seen in both field samples and inoculated roots. As the periderm is colonized, it darkens, becoming dark red to almost black in color. When roots surfaces are allowed to dry, however, reddish colors often fade to a dark brown. The symptoms generally are confined to the surface tissues of the root; this characteristic is also seen in carrot black spot, caused by $R$. carotae. We note, however, that Årsvoll (4) reported that $R$. carotae could, in addition, cause both dampingoff of carrot seedlings and foliar lesions. He suggested that wounded roots might be severely rotted by the pathogen. It is possible, therefore, that the ginseng isolates may cause other diseases of ginseng in addition to rusted root.

The detection of Rhexocercosporidium DNA in diseased roots following PCR with the ITS5/ITS4 primer set suggests that significant amounts of DNA of this fungus are present in diseased roots. No other fungus was detected as frequently using the ITS5/ ITS4 primer set; the ONBCU3/ONBCL2 primer set confirmed the high frequency of Rhexocercosporidium spp. in diseased tissue. PCR products found when using this primer set were identical to those from the Rhexocercosporidium sp. isolated from rusted roots. By contrast, Fusarium spp. were found to be at a lower frequency and, more importantly, were detected less consistently, varying greatly in incidence from field to field. This suggests that $F$. equiseti and $F$. culmorum are not common causal agents of rusted root, although they may be pathogenic (24). The disease appears to occur with a high rate of frequency in the absence of these Fusarium spp.; however, they may contribute to disease severity when present. There was no apparent correlation between the level of disease observed in samples and the detection rate of these Fusarium spp.

Roots without any apparent symptoms of rusted root were rarely positive for Rhexocercosporidium spp.; as might be expected, the frequency of detection of Rhexocercosporidium spp. in healthy-appearing tissue on otherwise rusted roots was higher. When collecting roots from field plots for pathogenicity tests, we observed that apparently healthy roots occasionally would develop the initial blister lesion phase of rusted root if stored under refrigerated conditions for a few weeks. Therefore, we suggest that roots collected from the field be stored or grown in greenhouse pots prior to use in pathogenicity tests.

We found only one rusted root extract sample that was positive for $F$. equiseti but negative for Rhexocercosporidium spp. Cylindrocarpon spp., F. solani, and F. oxysporum were detected inconsistently during ITS5/ITS4 PCR assays of diseased tissue; they appear to be secondary invaders. Bands representing this diverse group of fungi were common in samples from some fields but absent from others; thus, they are not likely to be primary causal agents. In separate tests not reported here, we found that, in bare-root assays, weakly aggressive strains of $C$. destructans (28) occasionally would cause small orange-red lesions on tap roots. These symptoms, however, were distinct from those observed on rusted roots. $F$. solani previously was reported as a pathogen of ginseng (23); however, this fungus is now regarded as saprophytic (24). F. roseum was found to be only weakly parasitic (27). A fungus causing a severe root rot of Asian ginseng ( $P$. ginseng) was first identified as $F$. solani (17) but later was found to be $C$. destructans (8). The high rate of detection of Rhexocercosporidium spp. in symptomatic tissue, as well as the ability of the fungus to reproduce disease symptoms, suggests that a Rhexocercosporidium $\mathrm{sp}$. is the predominant causal agent of this disease.

The use of PCR was essential to the surveys of diseased roots reported here. The MRBA medium was employed to isolate cultures from diseased roots; however, success often meant incubating tissue on the medium for up to 3 weeks, and cultures sometimes were overgrown by other fungi or bacteria during that time. However, we were able to observe Rhexocercosporidium cultures growing on diseased tissue samples from all fields plated onto MRBA. Therefore, the PCR data are consistent with observations of diseased tissue on the agar medium. General media or media that failed to suppress fast-growing fungi would have greatly reduced the likelihood of detection in diseased tissue. PCR methods have been shown to be at least as efficient as agar media in detecting pathogens in other crops $(9,15,16,32)$. The use of the PCR method to detect Rhexocercosporidium spp. allowed us to demonstrate that this fungus was associated with diseased root tissue at a high frequency, thus meeting the first of Koch's postulates. Inoculation of roots with Rhexocercosporidium spp. and recovery of the fungus from the resulting diseased roots allowed us to meet the remaining postulates.

Information regarding $R$. carotae suggested that the rusted root pathogen might be slow growing and cold tolerant $(4,29)$. When growth rates on agar of carrot isolates of $R$. carotae were compared with those of ginseng isolates of the Rhexocercosporidium fungus, we found that $R$. carotae and a soil Rhexocercosporidium isolate (DSE 48.1b) grew considerably more slowly. This, plus differences in the DNA sequences of the ITS region and differences in size of conidia (data not shown), suggest that the ginseng isolates are distinct from those previously reported from carrot and soil $(14,29)$. However, more detailed studies are required to determine whether the ginseng isolates are sufficiently distinct to merit being described as a new species. The genus Rhexocercosporidium was created to accommodate the carrot pathogen; thus, the genus has been viewed as a temporary solution to the nomenclature of that fungus and closely related organisms such as the ginseng Rhexocercosporidium sp. (29). Harrington and $\mathrm{McNew}$ (12) found that $R$. carotae was closely related to species of the anamorphic genera Rhyncosporium and Ramulispora, as well as the teleomorphic Discomycete genus Cladophora. Using sequence data reported here and GenBank sequences, we performed pairwise alignments between isolates of the ginseng Rhexocercosporidium sp. and Rhyncosporium secale. They were found to be $<92 \%$ similar. Thus, the ginseng rusted root pathogen appears to be more closely related to Rhexocercosporidium carotae than other similar fungi.

The agar growth rates reported here suggest that the fungus will be active throughout the cropping season and that soil temperatures under a cereal straw mulch will not rise sufficiently during the growing season to inhibit fungal growth. Thus, although the fungus is slow growing, we expect that there will be ample opportunities for infection and disease development. The source of inoculum for infections currently is unknown. Investigations of the distribution and ecology of the pathogen might result in useful options for disease management.

In this study, we used a combination of molecular and conventional techniques to detect and evaluate a new pathogen of ginseng. The approach outlined here may prove useful in assessing poorly described root diseases of other crops, particularly those caused by fungi that grow slowly on agar media.

\section{ACKNOWLEDGMENTS}

Funding for this project was supplied in part by the Matching Investment Initiatives Program of Agriculture and Agri-Food Canada, The Ontario Ginseng Growers Association, and The Associated Ginseng Growers of British Columbia. Sequencing was carried out at the Robarts Research 
Centre, University of Western Ontario, London, ON. We thank C. Babcock (Canadian Collection of Fungal Cultures, Ottawa, ON), R. Clear (Canadian Grain Commission, Winnipeg, MB), K. Dobinson (AAFC), C. Grau (University of Wisconsin-Madison), A. Osbourn (The Sainsbury Laboratory, Norwich, UK), J. Traquair (AAFC), and L. Wick (UFZ Centre for Environmental Research, Leipzig, Germany) for kindly supplying some of the cultures used in these studies; B. Capell and J. Miller for providing technical assistance; and several ginseng growers in Ontario and British Columbia for suppling diseased root samples for this study.

\section{LITERATURE CITED}

1. Altschul, S. F., Gish, W., Miller, W., Myers, E. W., and Lipman, D. J. 1990. Basic local alignment search tool. J. Mol. Biol. 215:403-410.

2. Anonymous. 2005. Production Recommendations for Ginseng. Publication 610. Ontario Ministry of Agriculture, Food and Rural Affairs. Queen's Printer for Ontario, Toronto, ON, Canada.

3. Årsvoll, K. 1965. Acrothecium carotae n. sp., a new pathogen on Daucus carota L. Acta Agric. Scand. 15:101-114.

4. Årsvoll, K. 1971. Acrothecium carotae. Sporulation, spore germination, and pathogenesis. Acta Agric. Scand. 21:3-10.

5. Brammall, R. A. 1994. Ginseng. Pages 194-299 in: Diseases and Pests of Vegetable Crops in Canada. R. J. Howard, A. J. Garland, and W. L. Seaman, eds. Canadian Phytopathological Society and Entomological Society of Canada, Ottawa, ON.

6. British Columbia Ministry of Agriculture, Food, and Fisheries. 2003. Annual BC Horticultural Statistics-2003. Statistics and Economics Unit, Policy and Economics Branch, Victoria, BC.

7. Campeau, C., Proctor, J. T. A., Jackson, C. J. C., and Rupasinghe, H. P. V. 2003. Rust-spotted North American ginseng roots: Phenolic, antioxidant, ginsenoside, and mineral nutrient content. HortScience 38:179-182.

8. Chung, H. S. 1975. Studies on Cylindrocarpon destructans (Zins.) Scholten causing root rot of ginseng. Rep. Tottori Mycol. Inst. (Jpn.) 12:127-138

9. Demeke, T., Clear, R. M., Patrick, S. K., and Gaba, D. 2005. Speciesspecific PCR-based assays for the detection of Fusarium species and a comparison with the whole seed agar plate method and trichothecene analysis. Int. J. Food Microbiol. 103:271-284.

10. Duke, J. A. 1989. Ginseng: A Concise Handbook. Reference Publications Inc., Algonac, MI.

11. Environment Canada. 2004. Canadian Climate Normals or Averages 1971-2000. National Climate Data and Information Archive, Meteorological Service of Canada, Downsview, ON.

12. Harrington, T. C., and McNew, D. L. 2003. Phylogenetic analysis places the Phialophora-like anamorph genus Cadophora in the Helotiales. Mycotaxon 87:141-151.

13. Hildebrand, A. A. 1935. Root rot of ginseng in Ontario caused by members of the genus Ramularia. Can. J. Res. 12:82-114.

14. Kohlmeier, S., Smits, T. H. M., Ford, R. M., Keel, C., Harms, H., and Wick, L. Y. 2005. Taking the fungal highway: Mobilization of pollutantdegrading bacteria by fungi. Environ. Sci. Technol. 39:4640-4646.

15. Konstantinova, P., Bonants, P., van Gent-Pelzer, M., van der Zouwen, P., and van den Bulk, R. 2002. Development of specific primers for detection and identification of Alternaria spp. in carrot material by PCR and comparison with blotter and plating assays. Mycol. Res. 106:23-33.

16. Luchi, N., Capretti, P., Pinzani, P., Orlando, C., and Pazzagli, M. 2005. Real-time PCR detection of Biscogniauxia mediterranea in symptomless oak tissue. Lett. Appl. Microbiol. 41:61-68.

17. Matuo, T., and Miyazawa, Y. 1984. Scientific name of Cylindrocarpon sp. causing root rot of ginseng. Ann. Phytopathol. Soc. Jpn. 50:649-652.

18. Mishra, P. K., Fox, R. T. V., and Culham, A. 2003. Development of a PCR-based assay for rapid and reliable identification of pathogenic Fusaria. FEMS Microbiol. Lett. 218:329-332.

19. National Agricultural Statistics Service. 2005. Wisconsin 2005 Agricultural Statistics, United States Department of Agriculture, Wisconsin Field Office, Madison, WI.

20. Nicholson, P., Simpson, D. R., Weston, G., Rezanoor, H. N., Lees, A. K., Parry, D. W., and Joyce, D. 1998. Detection and quantification of $F u$ sarium culmorum and Fusarium graminearum in cereals using PCR assays. Physiol. Mol. Plant Pathol. 53:17-37.

21. Ontario Ministry of Agriculture, Food and Rural Affairs. 2005. Ontario Ginseng Exports, 1997-2004. Science and Statistics Unit, Policy Development Branch, Guelph, ON.

22. Parke, J. L., and Shotwell, K. M. 1989. Diseases of Cultivated Ginseng. University of Wisconsin-Extension, Madison.

23. Punja, Z. K. 1997. Fungal pathogens of American ginseng (Panax quinquefolium) in British Columbia. Can. J. Plant Pathol. 19:301-306.

24. Punja, Z. K., Wan, A., and Rahman, M. 2005. Role of Fusarium spp. in rusty-root development on ginseng in British Columbia. (Abstr.) Can. J. Plant Pathol. 27:474.

25. Rayner, R. W. 1970. A Mycological Colour Chart. British Mycological Society and Commonwealth Mycological Institute, Kew, Surrey, UK.

26. Reeleder, R. D., and Hoke, S. M. 2005. Rusted root disease of ginseng (Panax quinquefolius). (Abstr.) Can. J. Plant Pathol. 27:462.

27. Reeleder, R. D., Roy, R., and Capell, B. 2002. Seed and root rots of ginseng (Panax quinquefolius) caused by Cylindrocarpon destructans and Fusarium spp. J. Ginseng Res. 26:151-158.

28. Seifert, K. A., McMullen, C. R., Yee, D., Reeleder, R. D., and Dobinson, K. F. 2003. Molecular differentiation and detection of ginseng-adapted isolates of the root rot fungus Cylindrocarpon destructans. Phytopathology 93:1533-1542.

29. Shoemaker, R. A., Hambleton, S., Lacroix, M., Tesolin, M., and Coulombe, J. 2002. Fungi Canadenses. No. 344 in: Rhexocercosporidium carotae. Can. J. Plant Pathol. 24:359-362.

30. Small, E., and Catling, P. M. 1999. Canadian Medicinal Crops. NRC Research Press, Ottawa, Ontario, ON, Canada

31. White, T. J., Bruns, T., Lee, S., and Taylor, J. 1990. Amplification and direct sequencing of fungal ribosomal RNA genes for phylogenetics. Pages 249-258 in: PCR Protocols: A Guide to Methods and Applications. M. A. Innis, D. H. Gelfand, J. J. Sninsky, and T. J. White, eds. Academic Press, Toronto, ON, Canada.

32. Zachova, I., Vytrasova, J., Pejchalova, M., Cervenka, L., and TavcarKalcher, G. 2003. Detection of aflatoxigenic fungi in feeds using the PCR method. Folia Microbiol. 48:817-821.

33. Zinssmeister, C. L. 1918. Ramularia root-rots of ginseng. Phytopathology 8:557-571. 